\title{
O PRINCÍPIO DA PREVALÊNCIA DOS DIREITOS HUMANOS
}

\author{
Flavia Veras Teixeira'
}

Resumo: A reflexão realizada nesse artigo abordará a evolução dos direitos humanos. O nascimento da Declaração Universal de Direitos Humanos e seus ideais advindos da Revolução Francesa, sob o lema da igualdade, liberdade e fraternidade, a evolução da soberania dos Estados em prol dos direitos humanos. O Brasil e os princípios da dignidade da pessoa humana e a prevalência dos direitos humanos previstos na Constituição de 1988. Bem como os critérios utilizados para incorporação dos tratados e convenções de direitos humanos no ordenamento jurídico brasileiro antes e após a Emenda Constitucional $\mathrm{n}^{\circ} 45$ de 30 de dezembro de 2004.

Palavras-chave: Constituição. Direitos humanos. Tratados internacionais. Prevalência.

\section{INTRODUÇÃO}

O mundo vive um momento de profundas transformações nas sociedades contemporâneas e nos valores que a sustentam. $\mathrm{Na}$ atualidade, os direitos da pessoa encontram-se crescentemente ameaçados. Sob essa ótica, torna-se imperiosa a neces-

\footnotetext{
1 Bacharel em Direito pela Faculdades Integradas do Brasil - UNIBRASIL em 2010. Pós-Graduada do XXIX Curso de Preparação à Magistratura do Paraná 2011. Pós-Graduanda da Escola da Magistratura do Trabalho - EMATRA 9a Região. Pós-Graduanda da Escola da Magistratura de Santa Catarina - ESMESC Núcleo Canoinhas. Cargo/função Voluntária na Assessoria $1^{\text {a }}$ Vara Cível de Canoinhas/ SC. E-mail: flavia.veras@tjsc.jus.br
} 
sidade de promover a proteção dos direitos humanos. Assim, entende-se por direitos do homem todos aqueles direitos que individuo possui pelo simples fato de existir, decorrentes de sua própria natureza humana e dignidade.

Numa perspectiva histórica, analisou-se os direitos humanos conquistados tanto no Brasil quanto no mundo, os pilares da dignidade humana que foi influenciada principalmente, pelo modelo francês de liberdade igualdade e fraternidade.

A Constituição de 1988, como instrumento de efetivação das garantias dos cidadãos, tem como uma de suas principais funções garantir a liberdade e, ao mesmo tempo, o pleno exercício de direitos, pois os seres humanos nascem iguais em direitos e liberdades. A vertente atual é dominante no planejamento do futuro quadro social do país, o interesse principal desta corrente é dar efetividade concreta aos direitos sociais, econômicos e culturais que representam direitos que a sociedade política tem o dever de garantir.

Dessa forma, o presente trabalho tem por objetivo enfocar a dignidade humana as inovações introduzidas pela Emenda Constitucional no 45/2004 no que tange aos tratados internacionais de direitos humanos diante da Constituição de 1988, conceituando-os e analisando-os em sua trajetória, até os dias atuais, bem como o conceito de homem livre e suas justificativas, a influência do jusnaturalismo, entre outros aspectos. Posteriormente, analisou-se a incorporação dos tratados internacionais de direitos humanos na Constituição de 1988, fazendo inicialmente uma abordagem pela sua historicidade, por meio de distinções e comparações com os países que serviram de referência para sua criação.

\section{A EVOLUÇÃO DOS DIREITOS HUMANOS}

Os direitos humanos possuem contornos tão remotos quanto o próprio homem. Assim, há de se enfatizar o pensa- 
mento de José Joaquim Gomes CANOTILHO "não gostaria de improvisar como historiador porque tem perfeita consciência do aviso [...] o perigo da história é que ela parece fácil e não o é". ${ }^{2}$ Portanto, "contentar-nos-emos com a apresentação <intriga>, avançando alguns tópicos para a compreensão do seu enredo". ${ }^{3}$

Nessa evolução, o indivíduo aferiu novos referenciais éticos e passou a ser o "núcleo radiante de valores universalmente reconhecidos" ${ }^{4}$, grande parte desses valores vieram ao mundo pela visão da antiga Grécia, a qual estabelecia a importância "da dignidade, à autonomia individual" 5 e a participação política, "o que levou muitos autores ao ponto de neles fundamentarem os direitos humanos". ${ }^{6}$ Por esse motivo o homem compõe o centro, a mola propulsora da sociedade, sua autonomia é reconhecida a partir da sua individualidade.

No entanto, cabe ressaltar que muitas sociedades foram construídas a partir do trabalho escravo, suas origens e justificativas compõem determinado momento histórico. Conforme elucida Aristóteles:

A utilidade que têm os escravos é quase a mesma dos animais domésticos: auxiliam-nos com sua força física em nossas diárias necessidades. A natureza mesma parece desejar dotar de características diferentes os corpos dos homens que são livres e dos que são escravos. Uns, efetivamente, são fortes para o trabalho a que são destinados; os outros são inteiramente inadequados para serviços tais, porém são de utilidade para a vida civil, que desta forma se encontra dividida entre os trabalhos da guerra e os da paz. Acontece, contudo, o contrário com muita frequência: existem indivíduos que possuem

2 CANOTILHO, José Joaquim Gomes. Estudos sobre direitos fundamentais. São Paulo: RT; Portugal: Coimbra Editora, 2008. p. 7.

3 Ibidem, p. 7.

4 CANELA JUNIOR, Oswaldo. Controle Judicial de Políticas Públicas. São Paulo: Saraiva, 2011. p. 26.

5 Ibidem, p. 26.

6 Ibidem, p. 26. 
apenas o corpo do homem livre, enquanto que outros dele apenas têm a alma. ${ }^{?}$

Os escravos eram considerados propriedades que passavam de pais para filhos. Suas funções eram bem delimitadas e permitiam compreender os valores daquela sociedade. A servidão nesse período não advinha de raças ou etnias, mas da derrota em guerras e do inadimplemento de dívidas. ${ }^{8}$

No caminhar dos séculos, a dignidade humana repousou nos alicerces da religião. No Cristianismo, a fé era guardiã das estruturas ${ }^{9}$, que por sua vez, tentou amenizar a escravidão. Segundo Nicanor Fávero Filho: "a influência do pensamento de Santo Agostinho e de São Tomaz de Aquino, que embora não condenassem a escravidão, apelavam para tratamentos mais dignos e caridosos com os escravos". ${ }^{10}$

Tomás de Aquino teve grande relevância para o direito, porque foi o primeiro autor a mencionar expressamente o termo dignidade humana. A religião católica pregava padrões de igualdade de filiação ${ }^{11}$ ao filho de Nazaré, no esforço de afastar qualquer tipo de discriminação pelo amor incondicional e, se expandiu da mesma forma que o budismo de Mahayana pelo mundo, como forma de dar nova conformação à história humana. ${ }^{12}$

$\mathrm{Na}$ Idade Média, os senhores feudais consideravam o homem como mero acessório de suas terras, suas moradias eram precárias e, estavam sujeitos a inúmeras restrições, como a "impossibilidade de casamento sem permissão ou de liberdade para poderem se deslocar para outras terras". ${ }^{13}$

7 ARISTÓTELES. Política. Coleção obra-prima de cada autor. Tradução por Torrieri Guimarães. São Paulo: Martin Claret, 2004. p. 19.

8 FÁVERO FILHO, Nicanor. Trabalho escravo: vilipêndio à dignidade humana. In: PIOVESAN, Flávia; Carvalho, LUCIANA Paula Vaz. (Coord.). Direitos humanos e o direito do trabalho. São Paulo: Atlas, 2010. p. 252.

9 CANELA JUNIOR, Oswaldo. Op. cit., p. 27.

10 FÁVERO FILHO, Nicanor. Op. cit., p. 252.

11 CANELA JUNIOR, Oswaldo. Op. cit., p. 28.

12 Ibidem, p. 28.

13 FÁVERO FILHO, Nicanor. Op. cit., p. 252. 
Os feudos aos poucos foram enfraquecendo em função das cruzadas, pestes, invasões e fugas em massa de colonos. A sociedade medieval cede espaço à sociedade urbana. Os homens passam a procurar trabalho e a reunir-se em associações. Nascem no século XII, as corporações do ofício. ${ }^{14}$

Nesse período a "jornada de trabalho era exaustiva, muitas vezes alcançando 18 horas diárias". ${ }^{15}$ Posteriormente "suprimidas com o advento da Revolução Francesa, em 1789, uma vez que foram consideradas incompatíveis com o ideal de liberdade do homem". ${ }^{16}$ Paralelamente houve "incentivo às Grandes Navegações e às conquistas de novos territórios na Ásia e América e à abertura de novos mercados consumidores para produtos manufaturados". ${ }^{17}$

No século XV, Portugal iniciou sua expansão territorial, tornando o primeiro país a expandir seus horizontes pelas águas do Atlântico. O Brasil Colônia, em seus 30 (trinta) primeiros anos, oferecia uma única matéria prima comercializada: o pau-brasil e, para isso, prevalecia à mão de obra nativa. Todavia, anos depois, um forte comércio se instalou na colônia e, esta, era submetida às ordenações da Coroa portuguesa, "imperavam, portanto, as Ordenações Filipinas, sob a influência do direito canônico e do direito romano." 18

Uma das principais atividades da colônia era a comercialização da cana-de-açúcar, utilizava-se exclusivamente mão de obra escrava. O comércio na Europa nesse período era controlado pelos holandeses. A cultura da cana-de-açúcar demandava excessiva mão de obra, o que intensificou o tráfico negreiro, concretizando a escravidão no país o qual "perdurou cerca de

14 COMPARATO, Fábio Konder. A afirmação histórica dos direitos humanos. 5. ed. rev. atual. São Paulo: Saraiva, 2007. p. 47.

15 SARAIVA. Renato. Direito do trabalho: versão universitária. 4. ed. rev. atual. São Paulo: Método, 2001. p. 31.

16 Ibidem, p. 31.

17 FÁVERO FILHO, Nicanor. Op. cit., p. 253.

18 REQUIÃO, Rubens. Curso de direito comercial. 28. ed. rev. atual. São Paulo: Saraiva, 2009. v. 1. p. 15. 
três séculos, e importou na utilização de cerca de 4 milhões de pessoas". ${ }^{19}$

A escravidão entrou em declínio somente no século XIX, sendo os principais fatores desencadeantes: a Revolução Industrial, devido às inovações do capitalismo, aliada aos ideais liberais e a emancipação das colônias na América. $O$ trabalho forçado e penoso foi o traço marcante da evolução histórica do país, além de largamente repreendida, a dignidade humana não era suficiente para acabar com a condição arbitrária que o homem estava exposto.

Com a pressão inglesa, que culminou na abolição da escravidão em 1889, outro problema instalou-se no Brasil, a falta de preparo e proteção para o ingresso de homens e mulheres no mercado de trabalho.

Salienta-se que muitas das noções filosóficas da pessoa humana e a luta contra escravidão pousam sobre a noção de direito natural, ou seja, influenciaram o pensamento iluminista, proporcionando ideais para as futuras declarações. ${ }^{20}$ Para John Locke, todos os homens são livres e iguais. O filósofo contribuiu para as ideias da Declaração Americana de 1776, ${ }^{21}$ sobretudo no artigo $1^{\circ}$ (primeiro), o qual foi considerado o primeiro ato formal de declaração dos Direitos Humanos, uma vez que, a Magna Charta ${ }^{22}$ de 1215, o Habeas Corpus Act de 167923, o Bill of Rights $^{24}$ de 1689 foram indicadores dos males do poder absoluto, objetivando apenas a proteção de determinados direitos. ${ }^{25}$

Locke foi o último filosofo a tentar justificar racionalmente a escravidão ${ }^{26}$, o que deixa claro sua contradição de pensamento,

19 FÁVERO FILHO, Nicanor. Op. cit., p. 253.

20 CANELA JUNIOR, Oswaldo. Op. cit., p. 29

21 Ibidem, p. 23.

22 COOLEY, Thomas McIntyre. Princípios Gerais de Direito Constitucional: nos Estados Unidos da América. Tradução por Ricardo Rodrigues Gama. Campinas: Russel, 2002. p. 216.

23 REIS, Jair Teixeira dos. Direitos humanos: para provas e concursos. Curitiba: Juruá, 2006. p. 30.

24 Ibidem, p. 31.

25 CANELA JUNIOR, Oswaldo. Op. cit., p. 29.

26 Ibidem, p. 29. 
pois admitia a existência de homens que não dispunham de condição humana, uma vez que legitimava o patrimonialismo..$^{27}$

Os filósofos Jean Jacques Rousseau ${ }^{28}$ romancista do século XIX e Charles Louis de Secondat, mais conhecido na história como o Barão de Montesquieu ${ }^{29}$, sofreram influências de autores como Groutius e Pufendorf, pois são conceitos repletos de voluntarismo jurídico do direito natural, os quais possuem reflexos sobre a Declaração dos Direitos do Homem e do Cidadão de 1789.30

Segundo MONTESQUIEU "O comércio afasta preconceitos destruidores; e é quase uma regra geral que, onde quer que haja costumes amenos, exista comércio e, onde quer que haja comércio, existam costumes amenos". ${ }^{31}$ Os iluministas sustentavam a noção de um padrão ético por meio de atos solenes, como forma de opressão aos regimes absolutistas na tentativa de alcançar a paz mundial, porém foram suprimidos pela disputa de terras e ocupações de mercados internacionais entre países, ocasionando a Primeira Guerra Mundial em 1914/18 de forma que a Liga das Nações Unidas foi dissolvida em 1942. ${ }^{32}$ Segundo Flávia PIOVESAN e Luciana CARVALHO:

[...] a primazia da pessoa humana, fundada na dignidade humana, é resposta à aguda crise sofrida pelo positivismo jurídico. Tal crise é emblemática associada à derrota do fascismo na Itália e do nazismo na Alemanha. Esses movimentos políticos

27 FACHIN, Luiz Edson; RUZIK, Carlos Eduardo Pianovski. Direitos fundamentais, dignidade da pessoa humana e o novo Código Civil: uma análise crítica. In: SARLET, Ingo Wolfgang. (Org.). Constituição, direitos fundamentais e direito privado. 2. ed. rev. amp. Porto Alegre: Livraria do Advogado, 2006. p. 94.

28 ROUSSEAU, Jean-Jacques. Discurso sobre a origem e os fundamentos da desigualdade entre os homens. Tradução por Lourdes Santos Machado. São Paulo: Abril Cultural, 1983. p. 259.

29 MONTESQUIEU, Charles Louis de Secondat. O espírito das leis. Tradução por Fernando Henrique Cardoso; Leôncio Martins Rodrigues. Brasília: Universidade de Brasília, 1995. p. 248.

30 CANELA JUNIOR, Oswaldo. Op. cit., p. 30.

31 MONTESQUIEU, Charles Louis de Secondat. Op. cit., p. 248.

32 CANELA JUNIOR, Oswaldo. Op. cit., p. 31. 
e militares ascenderam ao poder dentro do quadro da legalidade e promoveram a barbárie em nome da lei. ${ }^{33}$

O Tratado de Versalhes Parte XIII (1919) foi responsável pela criação da Organização Internacional do Trabalho (OIT). ${ }^{34}$ Nesse mesmo período, os absolutismos do nazismo e do fascismo criaram um poder arbitrário e totalitário, o antagonismo criado pelos países democráticos levou a Segunda Guerra Mundial em 1939/45. Período este, marcado por misérias, ódio, campos de concentração, aniquilamento de direitos humanos, e levaram a humanidade a perceber que o excesso de arbitrariedade no uso do poder representa uma ameaça à humanidade..$^{35}$

\section{A REVALORIZAÇÃO DO HOMEM NA SOCIEDADE PÓS-MODERNA}

O nascimento do Direito Internacional dos Direitos Humanos preconiza que toda nação deve respeitar os direitos dos seus cidadãos, os Estados e a Comunidade Internacional possuem "o direito e a responsabilidade de protestar, se um dos Estados não cumprir suas obrigações”. ${ }^{36}$

Portanto, por mais que a construção histórica e filosófica sobre os direitos humanos nos ofereça a noção de que os direitos e liberdades são inerentes dos indivíduos ${ }^{37}$, muitos destes direitos protetivos passaram a existir apenas no pós-guerra, uma vez que necessitaram de regulamentações espe-

33 PIOVESAN, Flávia; CARVALHO, Luciana Paula Vaz de. Direito ao trabalho e a proteção dos direitos sociais nos planos internacional e constitucional. In: (Coords.). Direitos humanos e o direito do trabalho. São Paulo: Atlas, 2010. p. 6.

34 PEREIRA, Cícero Rufino. Efetividade dos direitos humanos trabalhistas: o ministério público do trabalho e o tráfico de pessoas: o protocolo de palermo, a convenção n. 169 da oit, o trabalho escravo, a jornada exaustiva. São Paulo: LTr, 2007. p. 35.

35 CANELA JUNIOR, Oswaldo. Op. cit., p. 31.

36 PIOVESAN, Flávia. Temas de direitos humanos. 4. ed. São Paulo: Saraiva, 2010. p. 38.

37 BARROSO, Luís Roberto. Temas de direito constitucional. Tomo II. Rio de Janeiro: Renovar, 2003. p. 20. 
ciais como o próprio Direito Internacional dos Direitos Humanos. ${ }^{38}$

A proteção e regulamentação dos direitos não devem ser restritas aos Estados, pois revelam o interesse internacional e, trazem profundas consequências. ${ }^{39}$ Anteriormente, os Estados tratavam as questões sobre direitos do homem, como um problema de âmbito interno devido a sua soberania ${ }^{40}$, ou seja, "a proteção dos direitos humanos não deve se reduzir ao domínio reservado do Estado, porque revela tema de interesse legítimo internacional". ${ }^{41}$ No entanto, a partir de 10 de dezembro de 1948, foi aprovada a Declaração Universal dos Direitos Humanos, sob os sacramentos de Liberdade, Igualdade e Fraternidade, resgatando os ideais da Revolução Francesa. ${ }^{42}$

Hoje, não se admite a "existência de uma soberania absoluta e irrestrita, em decorrência da necessidade dos Estados buscarem a atuação de um conjunto em determinadas políticas, exigências da nova ordem mundial". ${ }^{43}$

Com a aprovação da Declaração dos Direitos Humanos, ratificaram "a Convenção Internacional sobre a Prevenção e Punição do Crime de Genocídio, aprovada um dia antes também no quadro da ONU". ${ }^{44}$ Estas "constituem os marcos inaugurais da nova fase histórica, que se encontra em pleno desenvolvimento". ${ }^{45}$ Fábio Konder COMPARATO explica que a Declaração dos direitos do homem é o marco definitivo da internacionalização dos direitos humanos. ${ }^{46}$

38 BARBOZA, Estefânia Maria de Queiroz. Jurisdição constitucional: entre o constitucionalismo e democracia. Belo Horizonte: Fórum, 2007. p. 133-134.

39 PIOVESAN, Flávia. Direito ao trabalho: e a proteção dos direitos sociais nos planos internacional e constitucional. p. 6.

$40 \mathrm{lbidem}$, p. 5.

41 Ibidem, p. 5.

42 CANELA JUNIOR, Oswaldo. Op. cit., p. 31.

43 GOMES, Eduardo Biacchi. Blocos econômicos: solução de controvérsias, uma análise comparativa a partir da união europeia e mercosul. 3. ed. rev. atual. Curitiba: Juruá: 2010. p.140.

44 COMPARATO, Fábio Konder. A afirmação histórica dos direitos humanos. 5. ed. rev. atual. São Paulo: Saraiva, 2007. p. 57.

45 Ibidem, p. 57.

46 Ibidem, p. 57. 
A Declaração Universal dos Direitos Humanos, inicialmente teve a concordância de 48 Estados, com 8 abstenções, ${ }^{47}$ mesmo assim, os direitos inerentes aos indivíduos passaram a refletir no mundo, por meio de uma uniformização de proteção dos mesmos, principalmente pelos Estados-partes. ${ }^{48}$ Tem-se, portanto, a "universalidade e indivisibilidade desses direitos". ${ }^{49}$ As ideias da Revolução Francesa foram retomadas sob uma roupagem universalista, de forma que o valor humano tornou-se essencial como uma necessidade de sobrevivência, os direitos humanos tornaram-se os bens mais caros da humanidade. ${ }^{50}$

A universalidade consiste na condição de pessoa, ou seja, "é o requisito único e exclusivo para a titularidade de direitos". ${ }^{51}$ Enquanto que a indivisibilidade é ineditamente "o catálogo dos direitos civis e políticos é conjugado ao catálogo dos direitos econômicos, sociais e culturais". ${ }^{52}$ Dessa forma, a declaração ajusta um "discurso tanto liberal quanto social de cidadania conjugando o valor liberdade ao valor da igualdade". ${ }^{53}$

Para Noberto BOBBIO, a maior problemática do nosso tempo com relação aos direitos humanos não seria fundamentá-los, mas sim protegê-los ${ }^{54}$, em suas palavras:

Não se trata de saber quais e quantos são esses direitos, qual é a sua natureza e seu fundamento, se são direitos naturais ou históricos, absolutos ou relativos, mas sim qual é o modo mais seguro para

47 PIOVESAN, Flávia. Direitos humanos: e o direito constitucional internacional. 12. ed. rev. atual. São Paulo: Saraiva, 2011. p. 195.

48 CARVALHO, Kildare Gonçalves. Direito constitucional: teoria do estado e da constituição: direito constitucional positivo. 15. ed. atual. amp. Belo Horizonte: Del Rey, 2009. p. 696.

49 PIOVESAN, Flávia. Temas de direitos humanos. p. 40.

50 CANELA JUNIOR, Oswaldo. Op. cit., p. 44.

51 PIOVESAN, Flavia. Direito ao trabalho: e a proteção dos direitos sociais nos planos internacional e constitucional. p. 7.

52 lbidem, p. 7.

53 PIOVESAN, Flávia. Temas de direitos humanos. p. 40.

54 BOBBIO, Noberto. A era dos direitos. Tradução por COUTINHO, Carlos Nelson. 9. ed. Rio de Janeiro: Elsever, 2004. p. 45. 
garanti-los, para impedir que, apesar das solenes declarações, eles sejam continuamente violados. ${ }^{55}$

Este conceito revela o sentido que o político dos direitos humanos ficou para trás, haja vista a necessidade de proteção individual. Para Diogo Pignataro de OLIVEIRA, os indivíduos antes da Declaração Universal de direitos humanos estavam à mercê da soberania estatal. ${ }^{56}$

Portanto, a partir da Declaração dos Direitos Humanos há uma maior participação dos Estados na proteção de direitos. Neste sentido, PIOVESAN esclarece, "a Segunda Guerra significou a ruptura com os direitos humanos, e o pós-guerra deveria significar a sua reconstrução". ${ }^{57} \mathrm{O}$ Direito Internacional alcançou grande produção normativa, dando maior centralidade aos seres humanos, "destinatários finais de todas as normas jurídicas". ${ }^{58}$

Parte da doutrina repousa sobre o conceito das gerações, o qual possui como pilar a igualdade, liberdade e fraternidade. Entretanto, importantes doutrinadores como Ingo Wolfgang SARLET defendem que o termo correto seria dimensões, uma vez que, a palavra gerações pode dar margem à interpretação de que uma geração possa substituir a outra. ${ }^{59}$

CANELA JUNIOR explica que "os direitos humanos são essenciais para o pleno desenvolvimento da vida em sociedade". ${ }^{60}$ Sua classificação em gerações ou dimensões somente é admitida como critério histórico, "não há diferenças hierárquicas ou prioridades entre os direitos humanos". ${ }^{61}$

55 Ibidem, p. 45.

56 OLIVEIRA, Diogo Pignataro. Os tratados de direitos humanos na contemporaneidade e sua aplicabilidade dentro da nova concepção constitucional brasileira: uma análise crítica a teor do $\S 3 .^{\circ}$ do art. $5 .^{\circ}$ da CF/88. Revista de Direito Constitucional e Internacional. São Paulo: Revista dos Tribunais, a. 16, n. 64. jul./set. 2008. p. 300.

57 PIOVESAN, Flávia. Direito ao trabalho: e a proteção dos direitos sociais nos planos internacional e constitucional. p. 5.

58 OLIVEIRA, Diogo Pignataro. Op. cit., p. 300.

59 SARLET, Ingo Wolfgang. A eficácia dos direitos fundamentais. 7. ed. rev. atual. Porto Alegre: Livraria do Advogado, 2007. p. 54.

60 CANELA JUNIOR, Oswaldo. Op. cit., p. 44.

61 Ibidem, p. 44. 
Portanto, cabe ao Estado a realização e cumprimento contemporâneo desses direitos. ${ }^{62}$

É importante ressaltar que por meio da Resolução "32/130 da Assembleia Geral das Nações Unidas: todos os direitos humanos, qualquer que seja o tipo a que pertencem se inter-relacionam necessariamente entre si" ${ }^{63} \mathrm{E}$ este posicionamento reiterou-se na Declaração de Viena de 1993, com relação à universalidade, indivisibilidade e independência dos Direitos Humanos. ${ }^{64}$

Um dos maiores instrumentos da Declaração Internacional de Direitos Humanos é em relação à forma de atuação dos Estados, como também os parâmetros a serem seguidos por seus membros, principalmente no que tange a violação dos Direitos Humanos levando a deslegitimação do Estado, em caso de violação e a desaprovação pela Comunidade Internacional.65

Trata-se de um "sistema normativo global de proteção dos Direitos Humanos, no âmbito das Nações Unidas" ,66 ou seja, os Direitos Humanos são reconhecidos diante de sua positivação por meio de Tratados, Convenções e Declarações de Direitos Humanos. ${ }^{67}$

Por fim, estes direitos integram a órbita interna dos países por meio de suas Constituições, bem como consagrando valores compondo um conjunto de regras e princípios que fazem parte do jus cogens, que consistem em normas gerais imperativas na esfera internacional. ${ }^{68}$

Os instrumentos de proteção dos Direitos Humanos asseguram sua efetiva aplicabilidade no âmbito interno. É dever de o

62 Ibidem, p. 44.

63 PIOVESAN, Flávia. Temas de direitos humanos. p. 43.

64 Ibidem, p. 43.

65 PIOVESAN, Flávia. Direito ao trabalho: e a proteção dos direitos sociais nos planos internacional e constitucional. p. 9.

66 Idem. Temas de direitos humanos. p. 44.

67 SILVA, Leila Maria Bittencourt da. Direitos humanos na teoria e na prática. Rio de Janeiro: GZ, 2009. p. 41.

68 MAZZUOLI, Valério de Oliveira; MEDEIROS, Antônio Cachapuz de. Desafios do Direito Internacional Contemporâneo: Jornada de Direito Internacional Público no Itamaraty Brasília: Fundação Alexandre de Gusmão, 2007. p. 266. 
Estado instituir critérios de aplicação imediata no que tange ao conteúdo dos Tratados e Convenções que protegem os "valores supremos da igualdade, da liberdade e da fraternidade entre os homens". ${ }^{69}$

Embora significativos sejam os avanços históricos de proteção da dignidade humana, é imprescindivel a construção de novos mecanismos para a efetivação desses direitos. Joaquim Herrera FLORES assevera que os direitos humanos "são processos, ou seja, o resultado sempre provisório das lutas que os seres humanos colocam em prática para ter acesso aos bens necessários à vida". ${ }^{70}$

No entendimento do autor, a aplicação da norma internacional possui como característica primordial não desafiar a norma interna, principalmente quando se trata de proteção dos seres humanos. O que se busca, portanto, é maior aplicabilidade dos tratados que versam sobre direitos humanos nas esferas internas dos Estados, sobretudo, com relação ao Brasil. ${ }^{71}$

Conclui-se que há uma necessidade constante de criação e implementação de mecanismos efetivos e necessários para a garantia dos direitos inerentes aos indivíduos, bem como maior atuação dos Estados consagrando em suas Constituições o respeito à dignidade da pessoa humana e a garantia do seu pleno desenvolvimento.

\section{O PROCEDIMENTO DE INCORPORAÇÃO DOS TRATADOS INTERNACIONAIS NO ORDENAMENTO JURÍDICO INTERNO}

O Brasil seguiu a evolução de outros países signatários da Declaração Universal com relação à incorporação dos Tratados Internacionais de Direitos Humanos. Segundo Flavia

69 COMPARATO, Fábio Konder. Op. cit. p. 226.

70 FLORES, Joaquim Herrera. A (re) invenção dos direitos humanos. Tradução por GARCIA, Carlos Roberto Diogo; SUXBERGER, Antonio Henrique Graciano; DIAS, Jefferson Aparecido. Florianópolis: Fundação Boiteux, 2009. p. 34.

71 Ibidem, p. 34. 
PIOVESAN é "a partir do processo de democratização do país, deflagrado em 1985, que o estado brasileiro passou a ratificar relevantes tratados internacionais de direitos humanos"..$^{22}$ Ainda, segundo a autora, "é nesse cenário que à temática dos direitos humanos começa a se consolidar como uma das mais relevantes pautas da agenda internacional do Brasil contemporâneo". ${ }^{73}$

Desta forma, a Constituição é suprema em relação às demais normas do ordenamento jurídico pátrio. ${ }^{74}$ Acompanha este entendimento, MORAES, no sentido que "a Constituição Federal de 1988 não exclui a existência de outros direitos e garantias individuais, de caráter infraconstitucional, decorrentes dos atos e tratados internacionais em que a República Federativa do Brasil seja parte". ${ }^{75}$

O processo de incorporação possui como marco inicial a ratificação da Convenção contra a Tortura e Outros Tratamentos Cruéis, Desumanos ou Degradantes em 1989. Este marco deu início à ratificação de importantes instrumentos referentes aos Direitos Humanos, pela Carta Magna de 1988. ${ }^{76}$

Contudo, é importante mencionar que o "tratado internacional é o acordo entre dois ou mais sujeitos da Comunidade Internacional que se destina a produzir determinados efeitos jurídicos". ${ }^{77}$ MORAES explica que existem várias nomenclaturas para a realização dos negócios jurídicos entre os Estados, como: "tratados, atos, pactos, cartas, convênios, convenções, protocolos de intenções, acordos, entre outros, sem que haja significativa alteração em suas naturezas jurídicas". ${ }^{8}$

72 PIOVESAN, Flávia. A Constituição brasileira de 1988 e os tratados internacionais de proteção dos direitos humanos. EOS Revista Jurídica da Faculdade de Direito, Curitiba, v.2, n. 1, p. 20-33. Disponível em: <http://www.dombosco.com. br/faculdade/revista_direito/3edicao/3\%C2\%AA\%20edi\%C3\%A7\%C3\%A3o\%20 completa. pdf>. Acesso em: 04 abr. 2011. p. 24.

73 PIOVESAN, Flávia. Direitos humanos: e o direito constitucional internacional. p. 342.

74 BARROSO, Luiz Roberto. O direito constitucional e a efetividade de suas normas: limites e possibilidades da Constituição brasileira. 9. ed. Rio de Janeiro: Renovar, 2009. p. 41.

75 MORAES, Alexandre de. Op. cit., p. 37.

76 PIOVESAN, Flávia. Temas de direitos humanos. p. 46.

77 MORAES, Alexandre de. Op. cit., p. 37.

78 Ibidem, p. 37. 
Nessa mesma linha, segue REZEK, ao afirmar que tratado é "todo acordo formal concluído entre pessoas jurídicas de direito internacional público e destinado a produzir efeitos jurídicos". ${ }^{79}$ PIOVESAN explica: "os tratados internacionais, enquanto acordos internacionais juridicamente obrigatórios e vinculantes (pacta sun servanda) constituem hoje a principal fonte de obrigação do Direito Internacional” ${ }^{80}$

No Brasil, o procedimento realizado para os tratados internacionais entrarem em vigor inicia-se pela fase de celebração conforme rege o artigo 84, inciso VIII, da Constituição. ${ }^{81}$

Neste caso, quando se refere à celebração dos tratados, a Constituição determina como competência exclusiva do Presidente da República. Não obstante a Carta Magna em seu artigo 49 , inciso I, ${ }^{82}$ determina a competência privativa de o Congresso Nacional deliberar a respeito de tratados, acordos ou atos internacionais que possam acarretar encargos ou compromissos gravosos ao patrimônio nacional. ${ }^{83}$

Sobre esta matéria de incorporação dos tratados, Carmem TIBURCIO explica que o percurso adotado pelo Brasil, inicia-se, então, pela "negociação entre as partes e a assinatura do texto final: incumbência do Presidente da República (CF, art. 84, VII e VIII), por intermédio de seu plenipotenciário" ". $\mathrm{O}$ segundo passo é a aprovação pelo Congresso Nacional "(CF, art. 49, I):

79 REZEK, Francisco. Direito internacional público: curso elementar. 11. ed. atual. São Paulo: Saraiva, 2008. p.11.

80 PIOVESAN, Flávia. Direitos humanos: e o direito constitucional internacional. p. 95.

81 BRASIL. Constituição (1988). Constituição da república federativa do Brasil: promulgada em 5 de outubro de 1988. PINTO, Antonio Luiz de Toledo; WINDT, Márcia Cristina Vaz dos Santos; CÉSPEDES, Lívia. (Orgs.). 39. ed. atual. São Paulo: Saraiva, 2006. p. 73.

82 Ibidem, p. 73.

83 PIOVESAN, Flávia. Direitos humanos: e o direito constitucional internacional. p. 100.

84 TIBURCIO, Carmen. A ec no 45 e temas de direito internacional. In: WAMBIER, Teresa Arruda Alvim; WAMBIER, Luiz Rodrigues; GOMES JUNIOR, Luiz Manoel; FISCHER, Octavio Campos; FERREIRA, William Santos. (Coords.). Reforma do judiciário: primeiros ensaios críticos sobre a ec n. 45/2004. São Paulo: RT, 2005. p.121. 
divulgada com a publicação de um decreto legislativo promulgado pelo Presidente do Congresso". ${ }^{85}$ A terceira fase pode assumir duas diferentes formas, nas palavras da autora:

a) Ratificação: ato do Chefe do Executivo no plano externo. Ocorre somente quando o Brasil assina o texto original do tratado. Se este for bilateral, ratifica-se pela via de troca de notas; se plurilateral, pelo depósito do instrumento de ratificação perante a organização internacional que tenha patrocinado a elaboração do acordo. Nos bilaterais, não cabem reservas, pois estas se consubstanciariam um novo tratado, nos multilaterais, salvo regra expressa em seu próprio texto, o Presidente da República pode opor reservas, para as quais se requer apenas a ciência (não anuência) das outras partes.

b) Adesão: ocorre quando o Brasil, sem ter firmado um tratado, quer posteriormente, ser parte dele. Os efeitos internacionais da adesão equivalem aos da ratificação; ${ }^{86}$

Em seguida, tem-se a Promulgação e Publicação que "visa à publicidade interna. O chefe do Executivo promulga e faz publicar um decreto em que se divulga o texto integral do pacto". ${ }^{87}$

Portanto, após a Emenda Constitucional no 45/2004, tem-se a possibilidade de institucionalização dos Tratados Internacionais de Direitos Humanos, a serem incorporados pelo ordenamento jurídico pátrio com status de norma constitucional. Então, para que seja incorporado com este status, deve cumprir o rito de emenda a Constituição. Dessa forma, além das fases procedimentais de incorporação os tratados que abordarem direitos humanos necessitarão ser analisados pelo crivo do Congresso Nacional obedecendo ao quorum privilegiado de aprovação. ${ }^{88}$

85 Ibidem, p. 121.

86 Ibidem, p. 122.

87 Ibidem, p. 122.

88 Ibidem, p. 122. 
Não obstante, é importante salientar que a assinatura do Presidente da República em um tratado internacional que verse sobre direitos humanos não gera nenhum efeito sem a aprovação do Congresso Nacional, pois segundo PIOVESAN são "dois atos completamente distintos: a aprovação do tratado pelo Congresso Nacional, por meio de um decreto legislativo e a ratificação pelo Presidente da República, seguida da troca ou depósito do instrumento de Ratificação". ${ }^{89}$

Entretanto, a Constituição Federal de 1988, não fez nenhuma referência com relação aos prazos que o Presidente da República possui para encaminhar o tratado para a aprovação do Congresso Nacional, bem como para sua devolução. Assim, não há dúvidas de que a competência para ratificar tratados é exclusiva do Presidente da República. Todavia, a aprovação ou rejeição incumbe ao Poder Legislativo, após este processo não há nenhuma forma de ingerência do Poder Executivo.

O Texto Magno de 1988, mesmo que por forma implícita não só incorpora os tratados internacionais como também apresenta uma distinção com relação aos tratados que versam sobre Direitos Humanos hierarquizando-os. Neste sentido, PIOVESAN explica:

Ao efetuar a incorporação, a Carta atribui aos direitos internacionais uma natureza especial e diferenciada, qual seja, a de norma Constitucional. Os direitos enunciados nos tratados de direitos humanos de que o Brasil é parte integram, portanto, o elenco dos direitos constitucionalmente consagrados..$^{90}$

Conclui-se, portanto, que ao analisar o artigo $5 .^{\circ}, \S 2 .^{\circ}$, observa-se que os tratados internacionais de direitos humanos possuem hierarquia constitucional e os demais tratados possuem hierarquia infraconstitucional, ou seja, de acordo com o artigo

89 PIOVESAN, Flávia. Direitos humanos: e o direito constitucional internacional. p. 101.

90 Ibidem, p. 104. 
102, III, alínea b, da CF/88 se "admite cabimento de recurso extraordinário de decisão que declarar a inconstitucionalidade do tratado ou lei federal". ${ }^{91}$

Com relação aos direitos fundamentais e artigo 5., § $2 .^{\circ}$, existem divergências doutrinárias sob a hierarquia dos tratados. ${ }^{92}$ Contudo, é importante mencionar que os direitos fundamentais devem ser considerados igualmente no seu aspecto material quanto formal. Para PIOVESAN:

[...] por força do $\S 2^{\circ}$ do mesmo artigo $5^{\circ}$ independentemente de seu quorum de aprovação, serão normas materialmente constitucionais. Contudo, para converter-se em normas também formalmente constitucionais deverão percorrer o procedimento demandado pelo $\S 3^{\circ} .{ }^{93}$

Com relação ao $\S 3 .^{\circ}$ introduzido ao artigo $5 .^{\circ}$ pela Emenda Constitucional 45/2004, tem-se a probabilidade de incorporação dos tratados de Direitos Humanos com hierarquia de Emenda Constitucional, porém desde que aprovados em cada casa do Congresso Nacional, em dois turnos, por três quintos dos votos dos respectivos membros.

Porém na hipótese de conflito entre a norma interna e o tratado internacional, tem-se como exemplo, a questão do depositário infiel. O inciso LXVII do artigo $5 .^{\circ}$ da Constituição Federal determina que "não haverá prisão civil por dívida, salvo a do responsável pelo inadimplemento voluntário e inescusável de obrigação alimentícia e a do depositário infiel”. No entanto o artigo 7. ${ }^{\circ}$, § 7. ${ }^{\circ}$ do Pacto de San Jose da Costa Rica explicita: "ninguém pode ser detido por dívida. Este princípio não limita os mandados de autoridade judiciária competente, expedidos em virtude de inadimplemento de obrigação alimentar”.

Em 2005, o Supremo Tribunal Federal no HC 72.131- RJ94 "sustentou a paridade hierárquica entre tratado e lei federal,

91 Ibidem, p. 112.

92 PIOVESAN, Flávia. Temas de direitos humanos. p. 55.

93 PIOVESAN, Flavia. Direitos humanos: e o direito constitucional internacional. p. 77. 94 Ibidem, p. 129. 
admitindo a possibilidade da prisão civil por dívida, pelo voto de oito dos onze Ministros" ${ }^{95}$.

O impacto causado pelo $\S 3 .^{\circ}$ do artigo $5 .^{\circ}$, da Constituição Federal de 1988 e a evolução jurisprudencial no que tange a proteção dos direitos humanos levaram o Ministro Celso de Mello no emblemático julgamento do HC 87.585-8, em 12 de março de 2008, sobre a problemática do depositário infiel a afirmar que:

O poder judiciário constitui o instrumento concretizador das liberdades constitucionais e dos direitos fundamentais assegurados pelos tratados e convenções internacionais subscritos pelo Brasil. Essa alta missão, que foi confiada aos juízes e Tribunais, qualifica-se como uma das mais expressivas funções politicas do poder judiciário. ${ }^{96}$

Na conclusão do julgamento o "Tribunal concedeu habeas corpus em que se questionava a legitimidade da ordem de prisão, por 60 dias, decretado em desfavor do paciente que intimado a entregar o bem do qual depositário, não adimplira a obrigação contratual". ${ }^{97}$

Todavia o Recurso Extraordinário no 466.343 de 2008 "conferiu aos tratados de direitos humanos uma hierarquia especial e privilegiada, com realce às teses da supralegalidade e da constitucionalidade desses tratados". ${ }^{98}$

\section{O PRINCÍPIO DA PREVALÊNCIA DOS DIREITOS HUMANOS}

A Carta Magna de 1988 é um modelo de Constituição Programática, porém não se limitou apenas em distribuir competências e garantir direitos. "Caracteriza-se pela substan-

95 Idem.

96 PIOVESAN, Flavia. Temas de direitos humanos. p. 56

97 SUPREMO TRIBUNAL FEDERAL. Informativo Brasília, 10 a 14 de março de 2008 n. 498. Disponível em: < http://www.stf.jus.br/arquivo/informativo/documento/informativo498.htm\#Prisão Civil e Depositário Infiel - 2>. Acesso em: 05 nov. 2012. 98 PIOVESAN, Flavia. Temas de direitos humanos. p. 129. 
tiva incorporação de princípios gerais, voltados a indicar um sentido de direção que a Constituição busca imprimir à sociedade brasileira". 99

Ela inova quando alberga o Princípio da Prevalência dos Direitos Humanos como princípio fundamental a reger o Estado brasileiro nas relações internas e externas. ${ }^{100}$ Celso LAFER explica: existe "no art. 4. ${ }^{\circ}$, clara nota identificadora da passagem do regime autoritário para o Estado Democrático de Direito" ${ }^{101}$, podendo dizer então que "este princípio afirma uma visão do mundo - que permeia a Constituição de 1988 - na qual o exercício do poder não pode se limitar à perspectiva dos governantes, mas deve incorporar a perspectiva de cidadania”. ${ }^{102}$

Tem-se, portanto, um grande desafio da Constituição. Kildare Gonçalves CARVALHO elucida que "o princípio da prevalência dos direitos humanos situa o homem como destinatário do direito internacional”. ${ }^{103}$ Desta forma, a posição do Brasil é a de opor-se aos Estados que desrespeitarem os direitos humanos. E, ao se referir à prevalência dos direitos humanos, o autor afirma que a Constituição possui ampla preocupação com estes direitos. ${ }^{104}$

O inciso II do artigo 4. ${ }^{\circ}$, "na prática diplomática brasileira tem sido uma política de direito voltada para adesão do Brasil aos Pactos Internacionais e Regionais de Direitos Humanos”. ${ }^{105}$ Assim, além da disposição do artigo $4 .^{\circ}$, II e parágrafo único, o conteúdo do parágrafo $2 .^{\circ}$ do artigo $5 .^{\circ}$, possibilita a criação de

99 LAFER, Celso. A constituição de 1988 e as relações internacionais: reflexões sobre o art. $4^{\circ}$ e sua relevância para os direitos humanos. Revista da Academia Brasileira de Direito Constitucional. Curitiba, n.7, p. 109-123, jan./jun. 2005. p. 112.

100 Art. $4 .^{\circ}$ da CF/88 "A República Federativa do Brasil rege-se nas suas relações internacionais pelos seguintes princípios: (...) II - prevalência dos direitos humanos;".

101 LAFER, Celso. A internacionalização dos direitos humanos: constituição, racismo e relações internacionais. São Paulo: Manole, 2005. p. 14.

102 Ibidem, p. 14.

103 CARVALHO, Kildare Gonçalves. Direito constitucional. 14. ed. Belo Horizonte: Del Rey, 2008. p. 661.

104 Ibidem, p. 661.

105 Ibidem, p. 13. 
mecanismos de cooperação para solucionar conflitos comuns entre os Estados, referentes à proteção dos direitos humanos, e uma das consequências da cooperação internacional é adequar às normas internacionais ao ordenamento jurídico interno. ${ }^{106}$

\section{CONCLUSÃO}

O presente trabalho não possui a pretensão de exaurir o tema, uma vez que aborda um assunto inesgotável. A Declaração Universal de direitos humanos é um marco da proteção às vítimas cidadãos dos Estados totalitários.

As sociedades ocidentais são baseadas nos pensamentos filosóficos que transformaram a dignidade humana como centro das relações interpessoais. Chegando a conclusão de que o homem é dotado de inteligência e autodeterminação. Os tratados de direitos humanos possuem grande relevância principalmente como forma de contribuir para a ascensão dos direitos humanos nos Estados-partes. No Brasil, o Princípio da Prevalência dos direitos humanos, previsto no artigo $4 .^{\circ}$, inciso II da Constituição rege o Estado no cenário externo, e, com isso, invoca a abertura da ordem jurídica no âmbito internacional.

A Declaração Universal de Direitos Humanos possui como características principais a universalidade e a indivisibilidade dos direitos. Quando se fala em universalidade significa dizer que todas as pessoas, independentemente da procedência nacional, cor, sexo ou orientação sexual, possuem direitos garantidos. Com relação à indivisibilidade, esta traz em seu bojo os direitos de três gerações ou dimensões, sem fazer distinção entre estes, porque não existe hierarquia entre os direitos de primeira, segunda ou terceira geração.

A partir da década de 60 foram criados dois pactos: o Pacto de Direitos Civis e Políticos de 1976 e o Pacto de Direitos Sociais Econômicos de 1975, o Brasil manifestou-se na adesão de ambos os pactos.

106 SLAIBI FILHO, Nagib. Reforma da justiça: notas à emenda constitucional n. ${ }^{\circ} 45$, de 08 de dezembro de 2004. Niterói, Impejus, 2005. p. 34 
$\mathrm{O}$ artigo $5 .^{\circ}$, parágrafo $2 .^{\circ}$, determina que os tratados de direitos humanos independentemente do quorum de aprovação são materialmente constitucionais e compõem o bloco de constitucionalidade.

A Emenda Constitucional n. 45/2004 introduziu o parágrafo $3 .^{\circ}$ do artigo $5 .^{\circ}$ determina o quorum qualificado. Portanto, essa alteração reforça a natureza constitucional dos tratados de direitos humanos e adiciona-os a um lastro formalmente constitucional, ou seja, são equiparados às emendas constitucionais, no entanto, é importante ressaltar que apenas o Pacto dos Portadores de Necessidades Especiais foi submetido ao crivo do artigo 5., § 3..$^{\circ}$ da Constituição.

O Texto Magno abrigou um sistema misto diferenciando da aplicação dos tratados de direitos humanos da aplicação dos demais tratados, o que assegura uma relação de equilíbrio e reciprocidade entre os Estados como garantia da dignidade da pessoa humana.

Abstract: The reflection made in this article will address the evolution of human rights. The birth of the Universal Declaration of Human Rights and its ideals stemming from the French Revolution, the slogan of equality, liberty and fraternity, the evolution of state sovereignty in favor of human rights. Brazil and the principles of human dignity and the prevalence of human rights under the Constitution of 1988. And the criteria used for incorporation of treaties and conventions on human rights in the Brazilian legal system before and after the Constitutional Amendment No. 45 of December 30, 2004.

Keywords: Constitution. Human rights. International treaties. Prevalence. 


\section{REFERÊNCIAS}

ARISTÓTELES. Política. Coleção obra-prima de cada autor. Tradução por Torrieri Guimarães. São Paulo: Martin Claret, 2004.

BARBOZA, Estefânia Maria de Queiroz. Jurisdição constitucional: entre o constitucionalismo e democracia. Belo Horizonte: Fórum, 2007.

BARROSO, Luís Roberto. Temas de direito constitucional. Tomo II. Rio de Janeiro: Renovar, 2003.

BOBBIO, Noberto. A era dos direitos. Tradução por COUTINHO, Carlos Nelson. 9. ed. Rio de Janeiro: Elsever, 2004.

BRASIL. Constituição (1988). Constituição da república federativa do Brasil: promulgada em 5 de outubro de 1988. PINTO, Antonio Luiz de Toledo; WINDT, Márcia Cristina Vaz dos Santos; CÉSPEDES, Lívia. (Orgs.). 39. ed. atual. São Paulo: Saraiva, 2006.

CANELA JUNIOR, Oswaldo. Controle Judicial de Políticas Públicas. São Paulo: Saraiva, 2011.

CANOTILHO, José Joaquim Gomes. Estudos sobre direitos fundamentais. São Paulo: RT; Portugal: Coimbra Editora, 2008.

CARVALHO, Kildare Gonçalves. Direito constitucional. 14. ed. Belo Horizonte: Del Rey, 2008.

COMPARATO, Fábio Konder. A afirmação histórica dos direitos humanos. 5. ed. rev. atual. São Paulo: Saraiva, 2007.

COOLEY, Thomas McIntyre. Princípios Gerais de Direito Constitucional: nos Estados Unidos da América. Tradução por Ricardo Rodrigues Gama. Campinas: Russel, 2002.

FACHIN, Luiz Edson; RUZIK, Carlos Eduardo Pianovski. Direitos fundamentais, dignidade da pessoa humana e o novo Código Civil: uma análise crítica. In: SARLET, Ingo Wolfgang. (Org.). Constituição, direitos fundamentais e direito privado. 2. ed. rev. amp. Porto Alegre: Livraria do Advogado, 2006.

FÁVERO FILHO, Nicanor. Trabalho escravo: vilipêndio à dignidade humana. In: PIOVESAN, Flávia; Carvalho, LUCIANA Paula Vaz. (Coord.). 
Direitos humanos e o direito do trabalho. São Paulo: Atlas, 2010.

FLORES, Joaquim Herrera. A (re) invenção dos direitos humanos. Tradução por GARCIA, Carlos Roberto Diogo; SUXBERGER, Antonio Henrique Graciano; DIAS, Jefferson Aparecido. Florianópolis: Fundação Boiteux, 2009.

FLORES, Joaquim Herrera. A (re) invenção dos direitos humanos. Tradução por GARCIA, Carlos Roberto Diogo; SUXBERGER, Antonio Henrique Graciano; DIAS, Jefferson Aparecido. Florianópolis: Fundação Boiteux, 2009.

GOMES, Eduardo Biacchi. Blocos econômicos: solução de controvérsias, uma análise comparativa a partir da união europeia e mercosul. 3. ed. rev. atual. Curitiba: Juruá: 2010.

LAFER, Celso. A constituição de 1988 e as relações internacionais: reflexões sobre o art. 4 e sua relevância para os direitos humanos. Revista da Academia Brasileira de Direito Constitucional. Curitiba, n.7, p. 109-123, jan./jun. 2005.

- A internacionalização dos direitos humanos: constituição, racismo e relações internacionais. São Paulo: Manole, 2005.

MONTESQUIEU, Charles Louis de Secondat. O espirito das leis. Tradução por Fernando Henrique Cardoso; Leôncio Martins Rodrigues. Brasília: Universidade de Brasília, 1995.

MORAES, Alexandre de. Tratados Internacionais na Constituição de 1988. In: AMARAL, Antonio Carlos Rodrigues de. (Coord.). Tratados Internacionais na Ordem Jurídica Brasileira. São Paulo: Aduaneiras, 2005.

OLIVEIRA, Diogo Pignataro. Os tratados de direitos humanos na contemporaneidade e sua aplicabilidade dentro da nova concepção constitucional brasileira: uma análise crítica a teor do $\S 3 .^{\circ}$ do art. $5 .^{\circ}$ da CF/88. Revista de Direito Constitucional e Internacional. São Paulo: Revista dos Tribunais, a. 16, n. 64. jul./set. 2008.

PEREIRA, Cícero Rufino. Efetividade dos direitos humanos trabalhistas: o ministério público do trabalho e o tráfico de pessoas: o protocolo de palermo, a convenção n. 169 da oit, o trabalho escravo, a jornada exaustiva. São Paulo: LTr, 2007. 
PIOVESAN, Flávia. A Constituição brasileira de 1988 e os tratados internacionais de proteção dos direitos humanos. EOS Revista Jurídica da Faculdade de Direito, Curitiba, v.2, n. 1, p. 20-33. Disponível em: <http://www.dombosco.com.br/faculdade/revista_ direito/3edicao/3\%C2\%AA\%20edi\%C3\%A7\%C3\%A3o\%20completa. pdf>. Acesso em: 04 abr. 2011.

. Direitos humanos: e o direito constitucional internacional. 12. ed. rev. atual. São Paulo: Saraiva, 2011.

Direitos humanos: e o direito constitucional internacional. 12. ed. rev. e atual. São Paulo: Saraiva, 2011.

- Direito ao trabalho e a proteção dos direitos sociais nos planos internacional e constitucional. In: PIOVESAN, Flávia; CARVALHO, Luciana Paula Vaz de. (Coords.). Direitos humanos: e direito do trabalho. São Paulo: Atlas, 2010.

. Temas de direitos humanos. 4. ed. São Paulo: Saraiva, 2010. 485 p.

. Trabalho escravo e degradante como forma de violação aos direitos humanos. In: NOCCHI, Andrea Saint Pastous; VELLOSO, Gabriel Napoleão; FAVA, Marcos Neves (Coords.). Trabalho escravo contemporâneo: o desafio de superar a negação. 2. ed. São Paulo: LTr, 2011.

REIS, Jair Teixeira dos. Direitos humanos: para provas e concursos. Curitiba: Juruá, 2006.

REQUIÃO, Rubens. Curso de direito comercial. 28. ed. rev. atual. São Paulo: Saraiva, 2009. v. 1.

REZEK, Francisco. Direito internacional público: curso elementar. 11. ed. atual. São Paulo: Saraiva, 2008.

ROUSSEAU, Jean-Jacques. Discurso sobre a origem e os fundamentos da desigualdade entre os homens. Tradução por Lourdes Santos Machado. São Paulo: Abril Cultural, 1983.

SARAIVA. Renato. Direito do trabalho: versão universitária. 4. ed. rev. atual. São Paulo: Método, 2001.

SLAIBI FILHO, Nagib. Reforma da justiça: notas à emenda constitucional n. ${ }^{\circ}$ 45, de 08 de dezembro de 2004. Niterói, Impejus, 2005. 
TIBURCIO, Carmen. A ec no 45 e temas de direito internacional. In: WAMBIER, Teresa Arruda Alvim; WAMBIER, Luiz Rodrigues; GOMES JUNIOR, Luiz Manoel; FISCHER, Octavio Campos; FERREIRA, William Santos. (Coords.). Reforma do judiciário: primeiros ensaios críticos sobre a ec n. 45/2004. São Paulo: RT, 2005. 